\title{
The Study of Evaluation the Quality of the Mobile Experiential Learning Model
}

\author{
Ya-Chin Kang1 ${ }^{*}$, Chia-Yi Chen² \\ ${ }^{1}$ Department of Labor Relations, Chinese Culture University, Taiwan \\ ${ }^{2}$ Department of Public Affairs \& Civil Education, National Changhua University of Education, Taiwan \\ Email: ^kangyaji@gmail.com, vivianchen087@gmail.com
}

How to cite this paper: Kang, Y.-C., \& Chen, C.-Y. (2016) The Study of Evaluation the Quality of the Mobile Experiential Learning Model. Creative Education, 7, 24902503.

http://dx.doi.org/10.4236/ce.2016.716236

Received: September 8, 2016

Accepted: October 22, 2016

Published: October 25, 2016

Copyright $\odot 2016$ by authors and Scientific Research Publishing Inc. This work is licensed under the Creative Commons Attribution International License (CC BY 4.0).

http://creativecommons.org/licenses/by/4.0/

\begin{abstract}
This study explores the learning behavior for the association of mobile learning and experiential learning. By performing on-site observation of the College Exploration Camp organized by the organization that is representative of youth experiential learning in Taiwan, a mobile experiential learning model is established. Suggestions for further research are also presented based on a survey of the camp leaders on the quality of their experience in order to evaluate the effectiveness of learning when combining mobile learning with experiential learning activities.
\end{abstract}

\section{Keywords}

Mobile Learning, Experiential Learning, Learning Quality Evaluation, Kano Model

\section{Introduction}

Experiential learning has been widely applied for many years. The present study investigates the diverse presentations of the training methods used in experiential learning. The explanation of the motivation behind the study and the problem statement follows.

In a competitive market where the emphasis is on efficiency, businesses are constantly seeking innovation and collaboration to stay healthy and sustainable. One of the main factors to achieving a successful transformation is team-building. A successful leader should be able to challenge, motivate, and energize the team through change. The question of how to establish high performance teams is the challenge that corporations in the 21st century face. Traditional training methods are classroom-based and has yielded inconsistent results; while "learning by doing" of experiential learning has gradually garnered reputation as one of the most effective methods for establishing high performance teams, and outstanding results have been achieved. In the US, the 
latter type of training has been implemented by corporations for some time. Many corporations consider this type of training as an important part of their training course. Through experiential team building activities, cooperation and mutual trust between employees are enhanced; and through difficult challenges, the potential of employees to innovate and solve difficult problems is stimulated (Scoot, 1988; Wagner, Baldwin, Roland et al., 1991).

Training refers to the systematic approach by an organization to assist its members to acquire abilities related to or required by their work. This includes knowledge, skill, and behavior, which can all affect work performance (Noe, 2006). In the past, training mainly focused on the teaching of the course. After realizing the importance of continued learning, training within organizations has gradually shifted towards learning, creation, and sharing (Noe, 2006).

Currently, most studies related to experiential learning have focused on the results of the activities. Most studies on experiential learning in Taiwan and abroad have focused on training results, self-realization, team atmosphere, self-concept, interpersonal relationships, internal and external control, self-esteem, interpersonal communication effectiveness, benefits of leisure, and performance in life. Relatively researches have been focused on the effectiveness of and the factors that influence experiential learning (Kolb, 2014). This is one of the main motivations for this study.

Furthermore, a mobile learning method that is learner-centered can identify potential learners such as the adult learner (Motiwalla, 2007), since adults normally have a clear understanding of their own notion of education and their needs (Knowles, 1973). Mobile learning is also more suitable for adult learners because their available time is fragmented due to work. In addition, that the Brandon Hall Group, a corporate performance enhancement and research organization in the US, created the "Best Use of Mobile Learning" award indicate that corporations have taken notice of the benefits of mobile learning. Outside of Taiwan, research has already been conducted on the incorporation of mobile learning to staff training programs at large corporations such as Merrill Lynch, Nike, and AT\&T.

Through actual participation and observation of the China Youth Corps College Exploration Camp, the author has found that the instructors have already gradually incorporated modern technology as a medium to conduct teaching, a novel concept compared to traditional experiential learning. Aside from implementation in parts of the experiential learning course, answering whether the integration of information technology into experiential learning will bring palpable results to learning is the second main motivation for this study.

Experiential learning uses the idea of "learn by doing" to revolutionize the regular education model. As technology develops at an ever-increasing pace, it can be incorporated with the traditional experiential learning model to create a new mobile experiential learning model. The current research has three objectives: 1) To investigate the methods for mobile experiential learning; 2) To investigate the factors that influences the introduction of mobile experiential learning in corporations; 3) To investigate the evaluation factors for improving training results for mobile experiential learning. 


\section{Literature Review}

The definition, process, and types of experiential learning; the definition and applications of mobile learning; and effectiveness evaluation are discussed as follows:

\subsection{Experiential Learning}

Experiential learning refers to the acquisition of knowledge and skills, and the process of improving one's self-worth through direct experience (AEE, 1995). The educationalist John Dewey coined the phrase "learn by doing". He believed that in the process of personal growth, in order for learning and for behavioral change to occur, an emphasis on "direct experience" is required. Direct, concrete, and actual experience is the way to truly learn (Dewey, 1938). In short, all learning that begins with activity, and is act first and learn after, can be categorized as experiential learning. The biggest difference between experiential learning and traditional training is that the former focuses on the learner (learner-centered), while the latter puts the center of attention on the teacher (teacher-centered). For training to be effective, the focus of the training should be on the trainee and not the trainer. As Galileo once said, "You cannot teach a man anything; you can only help him to find it within himself"; learning can be concentrated on the quality of understanding rather than on the quantity of information presented (AAAS, 1990).

Experiential learning is also known as "learning by discovery", "experience-based learning", "learning by activity", and "interactive learning". The benefits of experiential learning come from being student-centered. Besides being able to learn and experience the content on their own, the students can also learn at their own pace. Traditional education, characterized by listening, memorization, and examination, is passive rather than active; while experiential education, characterized by engagement, participation, and interaction, is highly active.

In experiential learning, the lesson plan should be designed with a specific, predetermined goal in mind. During the course of training, the student should be learning under the guidance of the instructor as opposed to being taught by the instructor. However, the biggest challenge to training is how the trainer and training course can motivate the student to learn by thinking on their own, and how to resonate with the student psychologically and behaviorally. At the same time, the course must inspire the student to challenge themselves, and to apply these experiences to the real world. As such, experiential education is marked by five characteristics: (Hsu, 2015):

1) It is a process and not a result.

2) It is a continuous process based on personal experience.

3) It is a comprehensive process of adapting to the world.

4) It involves an interaction between the learner and the environment.

5) It is a way of accumulating knowledge.

\subsection{The process of Experiential Learning}

Kraft and Sakofs (1985) believed that the process of experiential learning must include 
the following elements (Hsieh, 2015):

1) During the learning process, the learner should be a participant and not an observer.

2) During learning activities, personal motivation needs to be triggered to promote participation, proactivity towards learning, and sense of responsibility

3) The learning activities should be presented to the students in a natural manner in order to maintain relevance to real life.

4) The reflection of learners is a key element in the learning process.

5) Emotional changes are correlated with the present and future of the student and their organization.

Experiential learning should be analyzed before, during, and after the activities. The analysis can be roughly divided into five phases: Assessment, Planning, Preparation, Leading, and Evaluation, which are described below:

1) Assessment

The methods for assessment include written, interview, questionnaire, and attitude surveys. Assessment may occur during the experiential activity itself, if and when the activities are found to be impractical. The following questions about the participating group may help in examining the preparatory work for leading the group activities.

- Who: Who is this group?-What are the age, gender, and interests of the group? Is their participation voluntary or mandatory? Do they want to participate?

- What: What do they want to achieve upon completion of course?-What is the objective of the course? Are the objectives of the organizer and the participants identical? Are these objectives consistent, or are they contradictory? Do you have the confidence to achieve these objectives?

- How many: How many participants are involved?-Does the group consist of ten or two hundred people? Does the size of the group allow the objective to be achieved?

- How long: How long will the course be?-Is the time sufficient for achieving the objectives? Do you have enough class material, games, thoughts, and practical applications to complete the course?

- Where: Where will the course be held?-Indoors or outdoors? Do you need a larger space? If the weather is bad, or if there are too many people, do you have a backup location? Is the location safe enough?

- Other: Aare there any other special considerations?-Do they have experience with experiential learning? What is their expectation and understanding of the course?

2) Planning

Designing the setting according to the activities required by the group helps learners to apply what they have learned in their own lives. The plan can be examined using the following questions: What activities target the topics that the group needs to learn? What kind of icebreaker activities can help establish unity and trust? How many activities does it take to for individuals in the group to become comfortable with each other? How long will it take? If there is resistance from someone within the group, how will it be handled? With what words? Will students respond well to these types of dynamic games and problem solving activities? Or do adjustments need to make depending on 
their age, ability, and even weather conditions? How much information do they need and what do they want to get out of the course? How much time will there be for each activity? How to ensure that the activities have included all the items that must be checked-off? What sequence of activities (implementation framework) will produce the best results? How to close the course and what type of activities should be used? Which type of guidance and leading style will work the best? Planning includes the following:

- Being prepared to make adjustments to the plan.

- The course needs to be fun in order to keep the students energetic, interested, and motivated to learn. There are many forms of experiential learning, but all the best experiences include having fun. Having fun does not only mean games; Films, role-playing, creative art, skits, and magazine articles can all be used in a successful experiential learning course.

- Planning does not necessarily mean that everything needs to be serious. Unpredictable events, mischievous behavior, and unexpected or unplanned incidents should be handled with a respectful, positive, and appreciative attitude. All the activities should be carried out flexibly according to the spirit of experiential learning rather than strictly adhering to the fixed plan.

3) Preparation

Detailed arrangements for implementing the plan and activities should be made during the preparation phase. The preparation phase includes the following:

- Packing and inspecting the props needed or desired one by one.

- Discussing with the co-leader (if available) to ensure everyone is familiar with the plan.

- Inspecting the site first, then decide whether or not it is suitable especially for safety.

- Making ample preparations and making sure all the props are prepared by the time students arrive to reduce stress.

4) Leading

The key to leading is self-reflection, paying attention to what is going on, asking oneself why certain things are done, and then responding to observations and answering questions. Successful leadership depends on effective self-reflection. Practically speaking, leading entails creating suitable settings to emphasize the learning potential in activities; explaining the activity rules and making sure they are not violated; observing how teams achieve their objectives and the degree of their improvement; deciding whether intervention is required; deciding when and how to intervene to support the growth of the team; and sharing feedback on the activities to enable members to share their experiences with each other.

5) Evaluation

Evaluation is divided into evaluation during and after the course. Evaluation can point out common behaviors. Observe the team, their behavior and their course of development; analyze the behavior to decide whether the contents of the activity need to be adjusted; and provide further suitable challenges and guided discussions. Evaluation after the lessons can give the activity leader a chance to reflect on the session that has just com- 
pleted. This period of reflection is very helpful for the personal growth of the leader.

Strategically, the first step is to generate interest within the learner towards certain training courses, such as leadership, teamwork, organizational management, business marketing, interpersonal communication, outdoor leisure, guidance and counseling. As such, the emphasis is on the training requirements and completing the objectives, rather than the experiential learning method. Secondly, the format of the training needs to be unpredictable: sometimes the venue could outdoors and sometimes indoors; while novel, professional teaching materials and equipment should be used in order to evoke curiosity and motivation to learn from the students. The trainer should keep a low profile throughout the course. When the learners need information, the trainer may provide it for the learners to decipher the information, discuss, search for the answers on their own, and try their own solutions. Was it a success or a failure? Why? Through sufficient personal experience, learners will master the knowledge and techniques, and internalization thereof will change their behavior.

\subsection{Types of Experiential Learning}

There are many versions of experiential training methods. The more commonly seen methods include Outward Bound, Project Adventure (PA), Action-Learning, Scenario Planning, Team Coach. These are described below:

1) Outward Bound

Outward Bound mainly consists of Outward Bound training, extreme training, or experiencing nature. Outward Bound Schools has been established for many years outside of Taiwan, with three-day short training courses, and 14-day complete courses. Activities include land-based activities, water sports, and high altitude training. These courses integrate the natural environment, and emphasize experiencing the great outdoors and learning from nature to foster growth of the body, mind, and spirit. In Taiwan, examples of Outward Bound programs include OAO outdoor nature school hosted by Uni-President Enterprises Corporation, and the China Youth Corps Xiayun Discovery Education School, among others.

2) Project Adventure (PA)

Project Adventure (known as Discovery Education in Taiwan, and Adventure Education in Hong Kong) is mainly based on the third case in the Elementary and Secondary Education Act of 1965 in the United States. Courses include low, medium, and high level adventure training, and mainly apply psychological consultation and team building psychotherapy. Civic organizations and corporations have also gradually adopted its use; in recent years it has been introduced in Taiwan in response to course activation and other reform plans by the Ministry of Education. Discovery and experiential courses are also trending. Shida University's Department of Civic Education and Leadership, China Youth Corps, Asia Association for Experiential Education and other organizations have been actively promoting its use and has been designing courses based on experiential learning and using games to guide learning while stimulating the spirit of adventure at the right times; Locations for these courses include the Adventure 
Education Schools in Jinshan, Fuxing, Sun Moon Lake, Zengwen, and Cheng Ching Lake which are run by the China Youth Corps. There are also other places such as Wesley Grove the Methodist in Yangmingshan, Acer Aspire Park, National University of Tainan, Chenggongling District, and various other places.

\section{3) Action-Learning}

This is another program that is widely used. Action-Learning is mostly used in human resource and organizational management. Action-Learning takes "The Fifth Discipline" and "System Dynamics" from Peter Senge as the knowledge base, and is mainly used to assist in corporate staff training, organizational changes, and establishing learning-based organizations. Under the policies of the Taiwanese government of promoting learning-based corporations, families, schools, hospitals, and public agencies, the Civil Service Development Institute, National Chung Cheng University, China Productivity Center, Chinese Petroleum Corporation training center, Professor Showing Young's STOLL Laboratory in National Sun Yat-sen University, Taiwan Society for Organizational Learning, and other public and private training organizations all conduct Action-Learning courses.

4) Scenario Planning

Scenario Planning is a training tool for decision makers. In his book "Competitive Advantage", the expert strategist Micahel E. Porter discusses the use of scenario planning for devising competitive strategies in uncertain circumstances. This type of training is similar to computer dynamic role simulation games, and is mostly used in operational management in fictitious situations. While scenario planning was used in past by the American military during drills, corporations have adapted it as well, with Shell US serving as the best example. Management schools in Taiwan also have courses in scenario planning.

5) Team Coach

Team sports such as baseball, soccer, basketball all have a coach whose management skills ranges from sports to business to even life coaching. Their expertise covers physical, social, and spiritual fitness. The coach focuses on stimulating the physical potential and spiritual energy of the students, guiding them to return to and understand the self. Under the guidance of coaches, the students can in turn handle their own emotions, adjust their own attitudes and discern their needs and goals in life by living in the moment. Students are coached into top form for the best outcome. Management companies and growth/spiritual groups offer these types of training courses.

\subsection{Definition and Applications of Mobile Learning}

The use of technology for corporate training is no longer only for the unidirectional passing of information; the current trend is to encourage staff and to give feedback. Feedback provided by staff about the training, be it the course content or the learning outcome, becomes an important asset for the organization. In the concept of Web 2.0 proposed by O'Reilly (2005), one of the principles was "software above the level of a single device", meaning that learning is no longer confined to being in front of a desk- 
top computer. Presently, smartphones and tablets can be used as an information medium to facilitate mobile learning applications and corporate training. Downes (2005), who proposed the E-Learning 2.0 concept, believes that mobile learning not only creates opportunities, it also links together the learner, information, mobile tools and the rest of the world. Cross (2004) used the concept of workflow learning to describe education unconstrained by space and time (Downes, 2005) allowing the staff to improve their efficiency in a competitive corporation environment. The definitions of mobile learning, its characteristics, and its key areas of its usage in corporate training are elaborated below.

Due to the different perspectives and views from different researchers, no standard definition for mobile learning, or m-learning, exists (Motiwalla, 2007; Stone, 2010; Uzunboylu et al., 2009). A deconstruction of mobile learning into "mobile" and "learning", reveals that the main element of mobile learning is mobility. Using a mobile device, learners can learn at a time and in a space that is convenient for them. As learners gradually become accustomed to carrying around a mobile device, whether it is a smart phone or a tablet, they use it for various functions, such as for communication, and entertainment (Urmann, 2010). Most users therefore find that mobile devices are expedient. Being able to carry around the device allows the user to look for answers for any questions as they arise; the mobile device exemplifies immediacy.

The present study defines mobile learning according to the concepts presented by various researchers (Abernathy, 2001; Motiwalla, 2007; Stone, 2010; Uzunboylu et al., 2009). With emphasis on being able to learn anywhere, mobile learning is defined as "a mobile learner using a wireless network and mobile learning devices to learn by performing activities in a suitable time and location, in order to benefit from the convenience, expediency, and immediacy of mobile learning."

\subsection{The Implications of Training Performance Assessment}

A development and implementation of a complete training plan requires a systematic structure. According to the training development model proposed by Goldstein (1986), a set of complete training includes three phases: pre-evaluation, training program development, and post-evaluation of performance.

The Kirkpatrick Four-Level Training Evaluation Model was proposed in 1959, and is still used by corporations and governments today. It has four levels of evaluation indicators: reaction, learning, behavior, and result. The details of each of the four levels are explained below:

1) Reaction Level

Measures at the reaction level include the perceptions, sentiments, and subjective impression of the trainees of their experience of the course and the training activities. It represents the trainees' emotional response and attitude towards the training program. Although this level is the most common, it lacks correlation with the indicators for the three other levels. Regardless, the reaction level is still an important indicator, since the impression left on the trainee by the course will affect learning motivation and the level 
of commitment. Moreover, Kirkpatrick and Kirkpatrick (2006) also proposed that the outcomes from the higher levels can only be measured if the outcome of the lower levels changes, since if trainees are unsatisfied with the training they will be unwilling to learn and therefore unlikely to make progress at the next level.

2) Learning Level

The learning level is a measure of the level of improvement in learning objectives such as skill, knowledge, ability, and others (KSAO), as well as the overall progress of achieving the training objectives. The gap between the KSAO of the individual and that required to complete their work is where the learning should occur. Hence, Kirkpatrick and Kirkpatrick (2006) believe that if learning objectives are not reached, then behavior cannot be expected to change. The method of measurement depends on the nature of the evaluation and the type of learning. Common methods include written tests, applied practice, and examination. By performing pre-testing and post-testing comparisons, the improvements in the learning level indicators become more salient.

3) Behavioral Level

Behavioral level refers to the actual performance on the job. It is the influence of the training on the actual work performance, and the changes in behavior during work. As such, the topic of transfer of training commonly occurs in indicators at this level. Common measuring techniques include questionnaires, interviews, direct observation, comprehensive performance evaluation, and goal setting.

4) Result Level

The result level reflects the value of the benefits gained by the organization from the training, namely productivity and company profits. Utility analysis is also often used to evaluate the results. The result level is where the ultimate objective of the training lies. However, the data collection for indicators at this level is even more complicated than for the behavioral level. Kirkpatrick and Kirkpatrick (2006) explained that evaluation at this level is difficult because of factors such as the lack of understanding by the trainee of the evaluation mechanism; the length of time between the conclusion of the training and the manifestation of the effects; and the large number of variables that may affect training results.

In summary, this study established a mobile experiential learning model in order to understand the elements required for integrating mobile learning into experiential learning. Kirkpatrick's four level model was used to facilitate the performance evaluation for mobile experiential training.

\section{Methodology}

Literature review of research related to mobile learning, experiential learning, and training efficiency evaluation was performed. By consolidating past research within and without Taiwan, the conceptual framework of the present study was formulated. Based on the framework, training modules and result evaluation methods were established for mobile learning as applied to corporate experiential learning. 


\subsection{On-Site Observations}

In order to understand the benefits and barriers of mobile experiential learning for instructors, on-site observation of the practitioners of the experiential learning including teachers and planners was conducted. The observations also help to verify the feasibility of the mobile experiential learning model established by this study.

\subsection{Questionnaire Survey}

After a review of the relevant literature, a questionnaire is designed to investigate the satisfaction of the learner, the ability of the leaders, and the benefits of mobile experiential learning to the leading of activities. The Kano model is used to design and analyze the questionnaire. The questionnaires are targeted at the leaders who guide the mobile experiential learning activities in order to understand how mobile experiential learning is applied, analyze the behavior of the learner, and evaluate training outcome. Sixteen questionnaires were retrieved, where nine of the respondents were female and seven were male; the average age was 20.75; and the average number of camps they have led was 3.25 (Table 1).

\section{Results and Discussion}

The results of the mobile experiential learning model and the performance evaluation are discussed according to the objective of this study.

\subsection{Establish a Mobile Experiential Learning Model}

The subject for observation were experiential learning courses selected from the national university recreational instructors study camp from the 90th $(8 / 20 / 2015)$ and the 91st (1/23/2016) class of the summer and winter camps run by a professional Taiwanese youth experiential learning organization. The researcher conducted on-site observation of the course design, the use of technological tools such as laptops, and cell phones as a medium for instruction and guidance during the course. Feedback after the activities was also collected. The study found that compared to traditional experiential learning activities, mobile experiential learning enhanced the effects of learning (Table 2).

\subsection{Performance Evaluation for Mobile Experiential Learning}

Evaluation was performed on the results of the questionnaires filled out by the staff who participated in conducting the activities for the two classes, verifying the implications of mobile experiential learning. Investigation was carried out on the observations and experiences of the staff that used mobile devices during the course. The questionnaire was designed to be used for the investigation on three different fronts: course satisfaction; student knowledge and ability improvement; and staff leadership performance improvement. The correlation between mobile experiential learning and the responses "Yes/Sufficient" and "No/Insufficient" was also analyzed. The results categorized items into three types: A type (charismatic), $M$ type (basic), and $O$ type (expectation), as shown in Table 3. 
Table 1. Basic information of the activity leaders.

\begin{tabular}{ccc}
\hline Item & Type & Descriptive statistic \\
\hline \multirow{2}{*}{ Gender } & Male (1) & $7(44 \%)$ \\
& Female (2) & $9(56 \%)$ \\
Age & Years old & 20.75 \\
Camp leader experience & Times & 3.25 \\
\hline
\end{tabular}

Table 2. Characteristics of the mobile experiential learning model.

\begin{tabular}{|c|c|c|c|c|}
\hline & $\begin{array}{l}\text { Characteristics of mobile learning } \\
\text { Descriptions } \\
\text { of experiential learning activities }\end{array}$ & Convenience & Expediency & Immediacy \\
\hline $\begin{array}{c}\text { Assessment } \\
\text { phase }\end{array}$ & $\begin{array}{l}\text { The planner uses a mobile device to record the } \\
\text { assessment, which can be in various forms } \\
\text { including written, interview, questionnaire, and } \\
\text { attitude survey. The following questions may help } \\
\text { in examining the preparatory work for leading the } \\
\text { group. }\end{array}$ & V & V & $\mathrm{V}$ \\
\hline $\begin{array}{c}\text { Planning } \\
\text { phase }\end{array}$ & $\begin{array}{l}\text { Design experiential learning activities that are in } \\
\text { line with the goals and requirements while } \\
\text { ensuring that the course is flexible, diverse, and } \\
\text { fun. }\end{array}$ & V & V & V \\
\hline $\begin{array}{c}\text { Preparation } \\
\text { phase }\end{array}$ & $\begin{array}{l}\text { The planner examines and prepares the required } \\
\text { props and communicates with the co-leader to } \\
\text { ensure understanding of the plan. The planner } \\
\text { also checks the site for safety and suitability. } \\
\text { Relevant resources using mobile devices, such as } \\
\text { map searching, and image and text recording are } \\
\text { used. }\end{array}$ & V & $\mathrm{V}$ & $\mathrm{V}$ \\
\hline Leading phase & $\begin{array}{l}\text { Emphasize the learning objectives of the activity } \\
\text { at the appropriate time. Explain the activity rules, } \\
\text { monitor and observe the progress of the team } \\
\text { tasks. Intervene at appropriate times, support } \\
\text { team growth, give feedback on the activities, } \\
\text { and ensure the members are able to share their } \\
\text { experiences. The learners will use mobile devices } \\
\text { for the activities, such as uploading images, } \\
\text { locating position, relaying information. }\end{array}$ & V & V & V \\
\hline $\begin{array}{c}\text { Evaluation } \\
\text { phase }\end{array}$ & $\begin{array}{l}\text { Evaluate during and after the course to examine } \\
\text { the behavior and the development of the team. } \\
\text { Reflections can be recorded and progress } \\
\text { management can be performed using mobile } \\
\text { devices. }\end{array}$ & V & V & V \\
\hline
\end{tabular}

Analyzing the questionnaire responses revealed that the application of mobile devices increased the immediacy, convenience, and the flexibility of the course activities. The immediacy and convenience afforded by the mobile devices gave the activity leader room to make adjustments. The use of mobile devices also improved the understanding of the tasks and learning outcome of the students. 
Table 3. Kano categorization results for the performance quality of the mobile experiential learning model.

Performance quality questions for the mobile experiential learning model

A. Course satisfaction

1. Design of the contents in course activities

2. Scheduling of the course activities

3. The number of participants in the course activities

4. The use of mobile device improved the convenience of course activities

5. The use of mobile device improved the flexibility of course activities

6. The use of mobile device improved the immediacy of course activities

B. Student knowledge and ability improvement

1. The use of mobile devices helped students get to know each other

2. The use of mobile devices helped students understand the contents of the tasks

3. The use of mobile devices helped students carry out the tasks

4. The use of mobile devices helped students search for information

5. The use of mobile devices helped students complete the tasks

C. Staff leadership performance improvement

1. The use of mobile devices allowed you to carry out your leadership tasks more smoothly

2. The use of mobile devices makes you more willing to accept new challenges

3. The use of mobile devices allowed you to be more active in carrying out your leadership tasks

4. The use of mobile devices allowed you to respond better to problems that may occur during activities

5. The use of mobile devices improved your sense of accomplishment in leading the team

6. The use of mobile devices allowed you to promote the business better and improve the effectiveness of the activities

7. The use of mobile devices allowed you to reflect upon and feedback on the activity effectiveness

8. The use of mobile devices allowed you to develop your individual potential better

\begin{tabular}{|c|c|c|}
\hline Type & SI & DSI \\
\hline A & 0.42 & -0.08 \\
\hline A & 0.56 & -0.19 \\
\hline A & 0.19 & -0.06 \\
\hline A & 0.20 & 0.00 \\
\hline A & 0.53 & -0.07 \\
\hline A & 0.56 & -0.06 \\
\hline A & 0.47 & -0.07 \\
\hline A & 0.30 & -0.11 \\
\hline A & 0.13 & -0.19 \\
\hline A & 0.38 & -0.06 \\
\hline A & 0.31 & -0.06 \\
\hline A & 0.47 & -0.20 \\
\hline A & 0.25 & -0.06 \\
\hline A & 0.25 & -0.11 \\
\hline A & 0.40 & 0.00 \\
\hline A & 0.19 & -0.13 \\
\hline $\mathrm{O}$ & 0.13 & -0.13 \\
\hline A & 0.47 & -0.20 \\
\hline A & 0.13 & -0.07 \\
\hline A & 0.50 & -0.19 \\
\hline $\mathrm{M}$ & 0.07 & -0.07 \\
\hline $\mathrm{M}$ & 0.13 & -0.13 \\
\hline
\end{tabular}

A sensitivity matrix is obtained by mapping the distribution of the Kano quality categorization results, as shown in Figure 1. A circle is drawn with the origin 0 as the center and $\mathrm{OP}$ as the radius. Factors that are outside the radius and lie further away from the origin have greater sensitivity. From the data, the figure, and the sensitivity matrix, it can be deduced that the course satisfaction level is a factor that is highly influential. 


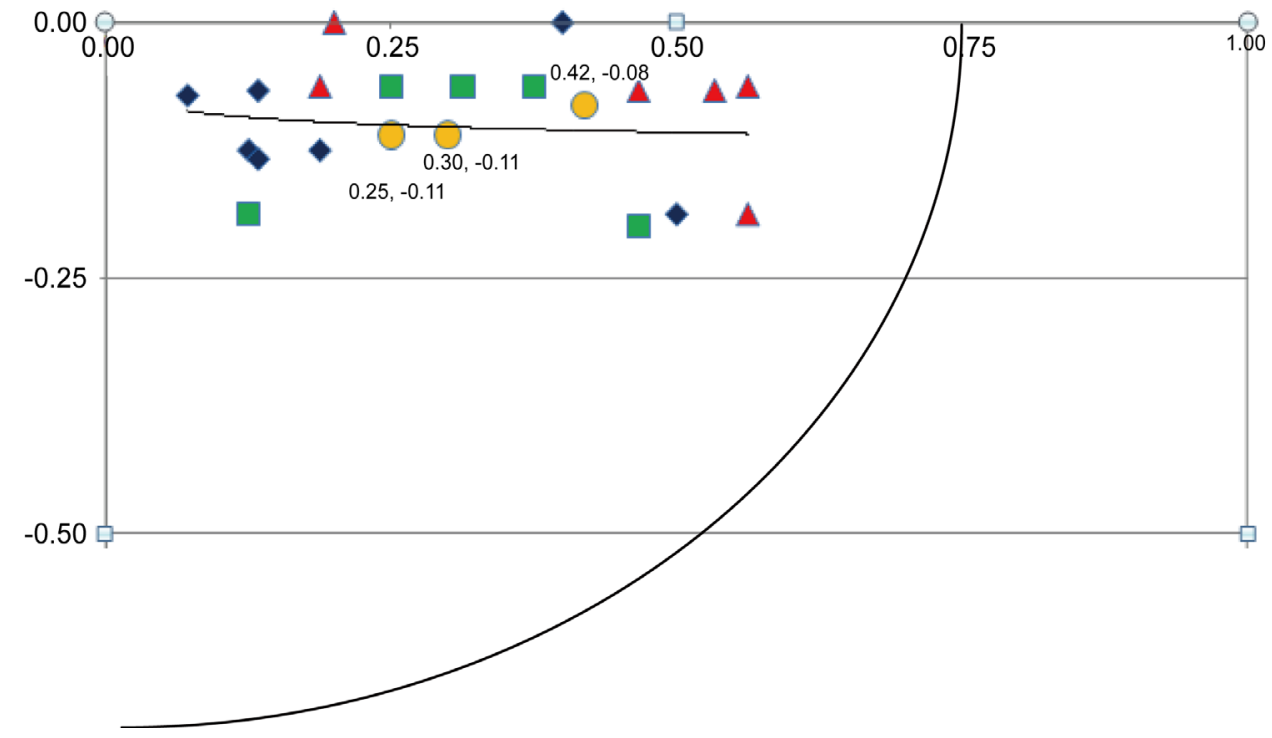

Figure 1. Kano results for the performance quality of the mobile experiential learning model.

\section{Suggestions}

With the advancement of modern technology, most course designs have already incorporated the use of mobile devices. Further investigation into the suitability of mobile devices for mobile experiential learning is carried out by the present study.

\section{Suggestions for the mobile experiential learning model}

The study revealed that mobile devices can be used in the training courses; however the number of ways that mobile devices can be used in experiential learning is limited. While using mobile devices in learning can certainly aid in the gathering of information and improving the transfer of information during group tasks, it can only be used when allowed by the circumstances. Only when the device and the onsite equipment allow for the learning method of scenario simulation can mobile devices be used. Even so, the students cannot experience physical contact that is to say if mobile devices are to be used in mobile experiential learning, it can only be incorporated into certain parts of the learning and is not able to form a complete learning experience.

\section{Suggestions for learning performance evaluation}

The introduction of mobile devices into mobile experiential learning improves the design of the course and allows students a certain level of convenience, immediacy, and also allows adjustments to the course in a timely manner. Mobile devices have already been integrated into the lives of most people, thus making it possibly an indispensable part of education. However, the course design must take into account whether the objective of the learner can be achieved by integrating the use of mobile devices. Furthermore, instead of relying completely on course designs that use modern technology and mobile devices, instructors must also prepare a back-up course plan that does not require modern technology to avoid affecting the class when mobile technology is not available. 


\section{References}

Abernathy, D. J. (2001). Get Ready for M-Learning. Training and Development, 20, 20-21.

AEE (1995). Association for Experiential Education. AEE definition of Experiential Education. The AEE Horizen, 15, 21.

American Association for the Advancement of Science (AAAS) (1990). Science for All Americans Online. http://www.project2061.org/publications/sfaa/online/Chap13.htm

Cross, J. (2004). What Is Workflow Learning? Retrieved 20 February 2012.

Dewey, J. (1938). Experience and Education. New York: Macmillan.

Downes, S. (2005). E-learning 2.0. Retrieved 20 February 2012. http://dx.doi.org/10.19173/irrodl.v6i2.284

Goldstein, I. L. (1986).Training in Organizations: Needs Assessment, Development, and Evaluation. Pacific Grove, CA: Books/Cole.

Hsieh, C. M. (2015). The Impacts of Adventure Therapy Training Workshops on High School Counselors' Adventure Therapy Competencies. 7th International Adventure Therapy Conference. Denver, CO.

Hsu, C.-H. (2015). Basic Theory on Experiential Education Tools, Reflections and Comparisons with General Teaching Methods PowerPoint Presentation. Unpublished.

Kirkpatrick, D. L., \& Kirkpatrick, J. D. (2006). Evaluating Training Programs: The Four Levels. San Francisco, CA: Berrett-Koehler.

Knowles, M. (1973). The Adult Learner: A Neglected Species. Retrieved from ERIC DatabaseED084368.

Kolb, D. A. (2014). Experiential Learning: Experience as the Source of Learning and Development. New Jersey: FT Press.

Kraft, R. J., \& Sakofs, M. (1985). The Theory of Experiential Education.

Motiwalla, L. F. (2007). Mobile Learning: A Framework and Evaluation. Computers \& Education, 49, 581-596. http://dx.doi.org/10.1016/j.compedu.2005.10.011

Noe, R. A. (2006). Employee Training and Development. Irwin: McGraw-Hill.

O’Reilly, T. (2005). What Is Web 2.0: Design Patterns and Business Model for the Next Generation of Software. http://www.oreilly.com/pub/a/web2/archive/what-is-web-20.html

Scoot, A. (1988). Outward Appearances. Accountancy, 102, 109-110.

Stone, T. (2010). Enterprise Mobile Learning and Development: A Guide for CLOs and Training Managers.

https://cdns3.trainingindustry.com/media/3579534/element $\% 20 \mathrm{k} \% 20$ enterprise $\% 20$ mobile $\% 2$ 0learning\%20and\%20development.pdf

Urmann, D. H. (2010). Expediency of Mobile Phones.

Uzunboylu, H., Vacus, N., \& Ercag, E. (2009). Using Mobile Learning to Increase Environmental Awareness. Computers \& Education, 52, 381-389.

Wagner, R., Baldwin, T., Roland, C., Schneir, C., Russell, C., Beatty, R., \& Baird, L. (1991). Outdoor Training: Revolution or Fad? Training and Development Sourcebook, 142-147. 
Submit or recommend next manuscript to SCIRP and we will provide best service for you:

Accepting pre-submission inquiries through Email, Facebook, LinkedIn, Twitter, etc. A wide selection of journals (inclusive of 9 subjects, more than 200 journals)

Providing 24-hour high-quality service

User-friendly online submission system

Fair and swift peer-review system

Efficient typesetting and proofreading procedure

Display of the result of downloads and visits, as well as the number of cited articles

Maximum dissemination of your research work

Submit your manuscript at: http://papersubmission.scirp.org/

Or contact ce@scirp.org 